\title{
Resistance and facilitation by native algal communities in the invasion success of Undaria pinnatifida
}

\author{
Glen A. Thompson, David R. Schiel* \\ Marine Ecology Research Group, School of Biological Sciences, University of Canterbury, Private Bag 4800, Christchurch, \\ New Zealand
}

\begin{abstract}
The mechanisms by which non-indigenous species overcome resistance in native communities are not well understood but are fundamental to the ability of invaders to persist and spread once they reach alien shores. One of the most widespread invaders is the kelp Undaria pinnatifida. Here we test disturbance, competition and facilitation in its recruitment into intertidal algal communities in southern New Zealand. In field-based experiments, we manipulated native fucoid and $U$. pinnatifida canopies, as well as the abundance and type of understory turfing species, and provided various gap sizes in native communities. Undaria pinnatifida recruitment occurred almost exclusively on coralline turf and in the absence of canopies, both native and conspecific. Where the native fucoid canopy was removed, $U$. pinnatifida recruited into gaps of all sizes $(5 \times 5 \mathrm{~cm}, 25 \times 25 \mathrm{~cm}, 50 \times 50 \mathrm{~cm})$, but the smallest gaps recovered their native canopy within several months and precluded further recruitment. Experimental manipulations of coralline turf showed that recruitment of $U$. pinnatifida was orders of magnitude greater where turf was present, regardless of the timing or sizes of clearances. Facilitation did not occur with other turfing species. Overall, native fucoids showed high resistance to invasion, but there was great facilitation by native coralline turf. Furthermore, as annual $U$. pinnatifida canopies disappear over summer, it is clear that coralline turf harbors the microscopic stages of $U$. pinnatifida that will form the following year's populations. As turfing species increase and persist following disturbances of native canopies worldwide, it can be expected that the recruitment dynamics of non-indigenous species will also change.
\end{abstract}

KEY WORDS: Fucoid · Canopy $\cdot$ Mechanisms $\cdot$ Facilitation $\cdot$ Competition $\cdot$ Turfing algae Resale or republication not permitted without written consent of the publisher

\section{INTRODUCTION}

There are many possible mechanisms by which non-indigenous species overcome local resistance and gain traction within native assemblages. In marine algal assemblages, these involve a combination of life-history traits of an invader, the characteristics of native communities, and ecological processes such as disturbance, competition and facilitation (Valentine \& Johnson 2003, Edgar et al. 2004, Valentine \& Johnson 2004, Britton-Simmons \& Abbott 2008, Mineur et al. 2008, Thomsen et al. 2009). The grow- ing number of successful invasions worldwide is testament to the numerous life-history traits and mechanisms that allow invaders to establish successfully (Valentine et al. 2007, Engelen \& Santos 2009). For example, plant fragmentation, such as in Caulerpa taxifolia, allows vegetative propagation, which can lead to high invasion success (Ceccherelli \& Cinelli 1999, Ceccherelli \& Piazzi 2001, Ceccherelli et al. 2002). In many other cases, fast turnover, high reproductive output and good dispersal allow regional spread along coastlines (Pedersen et al. 2005, Farrell \& Fletcher 2006, Russell et al. 2008). 
Once a marine invasive species has arrived to a coastline, often via man-made structures in sheltered areas (e.g. Airoldi \& Bulleri 2011), its movement to natural habitats and spread along a coastline can be determined by its ability to establish within often densely populated native communities (Forrest \& Taylor 2002, Bulleri et al. 2008, Raffo et al. 2009, Thomsen et al. 2009). At this stage of invasion, competitive effects through canopy shading, pre-emption of primary substratum and overgrowth may compromise the ability of an invader to establish viable populations (Britton-Simmons 2006, Scheibling \& Gagnon 2006, Dunstan \& Johnson 2007, Valentine et al. 2007, Thomsen et al. 2009). Conversely, disturbances that create gaps in natural communities may allow invasion (Valentine \& Johnson 2003, Edgar et al. 2004, Valentine \& Johnson 2004, Incera et al. 2010), and particular types of benthic cover may actually facilitate invasion (Bulleri \& BenedettiCecchi 2008, Bulleri et al. 2009, Bulleri et al. 2011). Unfortunately, in terms of management and in-depth understanding of processes, many of them are context-dependent (Thomsen et al. 2011). Subtidally, the presence of a dense native algal canopy has been shown to inhibit the invasion of marine alien species due to prior space occupancy and/or lack of resource availability (e.g. light), with successful invasion occurring only following native canopy removal (Valentine \& Johnson 2003, Edgar et al. 2004, Valentine \& Johnson 2004, Scheibling \& Gagnon 2006, Valentine et al. 2007, Bulleri et al. 2010). The timing of gap creation or disturbance is also important, with maximum recruitment of the invader occurring when the disturbance was just prior to its reproduction season (Valentine \& Johnson 2003, Incera et al. 2010, Airoldi \& Bulleri 2011). However, little work of this nature has been done in the intertidal zone (but see Sánchez \& Fernández 2006, Incera et al. 2010), which is modulated not only by algal canopies but also by often harsh and extreme physical conditions.

A decline of canopy-forming macroalgae is often associated with an increase in dense mats of turfing algae (Lilley \& Schiel 2006, Airoldi \& Beck 2007, Perkol-Finkel \& Airoldi 2010). Negative feedbacks can occur when turfing algae inhibit recruitment of native macroalgal species due to preclusion of suitable substratum for settling and their high retention of sediments (Airoldi 2000, Airoldi \& Beck 2007, Perkol-Finkel \& Airoldi 2010, Schiel 2011, Schiel \& Lilley 2011). Conversely, turfing algae have been shown to facilitate the recruitment of invasive macroalgal species (Ceccherelli et al. 2002, Bulleri \& Benedetti-Cecchi 2008, Bulleri et al. 2010) due to their physical structure offering greater surface area to catch algal fragments and spores, potential for water retention and refuge from grazers. On the coast of Italy, for example, Ceccherelli et al. (2002) demonstrated that the presence of algal turfs could directly increase recruitment of the invasive species Caulerpa racemosa and $C$. taxifolia. The complex physical structure of the turfs had a high surface area and trapped particles and stolons (Ceccherelli et al. 2002, Bulleri \& Benedetti-Cecchi 2008). Furthermore, these understory turfs may interact with algal canopies in suppressing growth and survival of invaders (BrittonSimmons 2006). With a well-documented global increase in the cover of turfing algae, there is therefore some concern about the consequent potential for greatly altered dynamics of invasive macroalgae species (Airoldi \& Beck 2007, Bulleri \& Benedetti-Cecchi 2008, Perkol-Finkel \& Airoldi 2010).

One of the most invasive macroalgal species is the Japanese kelp Undaria pinnatifida (Harvey) Suringer, which has become established in the temperate zone worldwide (Silva et al. 2002, Valentine \& Johnson 2003, Edgar et al. 2004, Farrell \& Fletcher 2006, Martin \& Cuevas 2006, Baez et al. 2010, Irigoyen et al. 2011). This seaweed arrived in New Zealand around 1987 and has since spread throughout much of the South Island (Hay \& Villouta 1993, Parsons 1995, Stuart 2004, Russell et al. 2008), aided by multiple incursions (Uwai et al. 2006). Once established, attempts at removing it have been mostly unsuccessful (Stuart 2004, Hewitt et al. 2005, Forrest \& Blakemore 2006, but see Wotton et al. 2004), presumably because of its fast growth rate and high reproductive output (Hay \& Villouta 1993, Dean \& Hurd 2007, Casas et al. 2008, Primo et al. 2010). Undaria pinnatifida is very efficient at using nutrients for quick growth and has an opportunistic life history (Schiel \& Foster 2006, Dean \& Hurd 2007, Russell et al. 2008). It is an annual species with macroscopic sporophyte and microscopic gametophyte phases. Large sporophytes between 1 and $2 \mathrm{~m}$ in length are most abundant during the winter and spring (Schiel \& Thompson 2012). Zoospores are released in spring and microscopic plant phases develop over summer (Stuart 1997, Thompson 2004, Schiel \& Thompson 2012). Undaria pinnatifida was initially thought to be restricted to sheltered harbors. For example, at the southern port of Moeraki, U. pinnatifida was discovered in 1987 but it took several years to spread along the local shoreline and over $10 \mathrm{yr}$ to spread along the open coast less than a kilometer away. At many southern coastal sites, it has now established large populations in the low inter- 
tidal zone, where it co-occurs with at least 6 species of fucoids and an understory of dense mats of coralline algae (Stuart 2004, Schiel 2006, Russell et al. 2008). Although the distribution of $U$. pinnatifida has been well documented, the mechanisms of establishment are less understood. Because of the slow spread of $U$. pinnatifida within localized sites, we initiated a study to test how it established within the dense native vegetation (Thompson 2004). Here we test the hypotheses that algal canopies, understory turfing species and disturbances of various sizes in native communities affect recruitment of $U$. pinnatifida on intertidal reefs in southern New Zealand.

\section{MATERIALS AND METHODS}

Experiments testing the effects of algal canopies and the cover of primary substratum on recruitment of Undaria pinnatifida were carried out at Diamond Harbor (4337' 31.61" S, $\left.172^{\circ} 43^{\prime} 04.13^{\prime \prime} \mathrm{E}\right)$ and Rapaki Bay $\left(43^{\circ} 36^{\prime} 28.65^{\prime \prime} \mathrm{S}, 172^{\circ} 40^{\prime} 53.46^{\prime \prime}\right.$ E) within Lyttelton Harbor, on the eastern coast of the South Island of New Zealand. Rapaki Bay is on the northern side of the harbor and is sheltered from prevailing winds, and Diamond Harbor is on the southern side of the harbor and is moderately wave exposed. The lower intertidal zone is approximately $5 \times 150$ and $5 \times 50 \mathrm{~m}$ at Rapaki Bay and Diamond Harbor, respectively. Both sites are formed from basaltic rock and the low zone is dominated by $U$. pinnatifida, particularly during the winter and spring months, the native fucoid Carpophyllum maschalocarpum and the coralline turfing alga Corallina officinalis. At Diamond Harbor there are patches of dense turf of the brown alga Halopteris congesta.

\section{Natural recruitment patterns}

The relationship between adult Undaria pinnatifida plants and recruitment was examined using monthly population surveys from June 2000 to May 2002. In each month, ten $0.25 \mathrm{~m}^{2}$ quadrats were randomly placed in the low zone at Diamond Harbor and the number and percent cover of adults and recruit (<50 mm total length) $U$. pinnatifida plants were recorded.

To examine whether Undaria pinnatifida recruited onto specific substratum types, ten $25 \times 25 \mathrm{~cm}^{2}$ quadrats were randomly placed within areas of differing dominant substrata in the low zone at Diamond Harbor and recruits were counted during autumn 2001. Substrata were grouped into 6 types: coralline turf (Corallina officinalis), small crevices ( $\sim \mathrm{cm}$ deep), other turfing species (e.g. Halopteris congesta), bare space, encrusting coralline algae and 'other' (mostly oyster and mussel shell debris).

\section{Native canopies and patch size effects on Undaria pinnatifida recruitment}

To test the hypothesis that the presence of native fucoid canopies affects recruitment of Undaria pinnatifida, and that an increased size of native canopy disturbance affects susceptibility to invasion by $U$. pinnatifida, 8 plots in each size class of $5 \times 5,25 \times$ 25 and $50 \times 50 \mathrm{~cm}$ were marked on the low shore at Rapaki Bay during August 2001. Portions of this site had a dense cover of the native fucoid Carpophyllum maschalocarpum; plants can reach approximately $1 \mathrm{~m}$ in length, are long-lived and can regenerate from damaged holdfasts (Schiel 1985). All plots had an original C. maschalocarpum cover of $>95 \%$ and the substratum had a mixture of coralline turf, encrusting coralline algae and bare space. Four plots in each size category were left unmanipulated and 4 had the native canopy of C. maschalocarpum removed just above the base of the holdfast to avoid damaging the substratum. The number of recruits and the percent cover of C. maschalocarpum and $U$. pinnatifida were monitored monthly until August 2002.

\section{Conspecific canopy effects on Undaria pinnatifida recruitment}

Ten $0.25 \mathrm{~m}^{2}$ plots dominated by Undaria pinnatifida (>95\% cover) were marked in the low shore at Rapaki Bay in July, August and September 2001. In each month, 5 of the plots had the adult canopy of $U$. pinnatifida removed just below the sporophyll, leaving the holdfast so as not to disturb the substratum and another 5 plots were left unmanipulated. The substratum in each plot was comprised mostly of coralline turf, but with small amounts of bare space. The number of recruits was monitored for 3 mo following canopy removal.

\section{Turfing algae, patch size and timing effects on Undaria pinnatifida recruitment}

To test whether disturbance to the substratum cover of coralline turf and the size of disturbed 
patches affected recruitment of Undaria pinnatifida in the absence of a canopy, 3 replicate plots of $5 \times 5$, $10 \times 10$ and $25 \times 25 \mathrm{~cm}$ were left dominated by coralline turf $(>90 \%$ Corallina officinialis, $\sim 2 \mathrm{~cm}$ high), and 3 plots of each size were scraped back to a primary cover of encrusting coralline and bare space. Removals were initiated in November 2000 and October 2001 and monitored monthly until May 2001 and May 2002, respectively.

The timing of substratum turf disturbance and its effects on recruitment of Undaria pinnatifida were tested within plots of $25 \times 25 \mathrm{~cm}, 3$ of which were left unmanipulated and 3 of which had the coralline turf Corallina officinialis scraped back to bare rock. These treatments were initiated in a new set of 6 patches every month from November 2000 to June 2001. Plots were monitored for the number of recruits monthly for 12 mo following the initial month of disturbance. There was no canopy cover over any of these plots.

To examine whether different species of turfing algae affected recruitment of Undaria pinnatifida and native fucoids, 6 replicate $25 \times 25 \mathrm{~cm}$ plots were marked in patches dominated by Corallina officinalis and 6 in areas dominated by the turfing form of the alga Halopteris congesta in November 2000 and October 2001. Three of the plots in each type of patch were left as unmanipulated controls and 3 had the turfing algae removed by scraping it back to bare substratum. Plots were monitored monthly for $7 \mathrm{mo}$ after initial removal to include recruitment over the autumn and early winter months.

\section{Interactive effects of canopy and turfing algae on Undaria pinnatifida recruitment}

In a separate set of treatments, the interactive effects of the conspecific canopy and turfing algae covering the substratum were examined by crossing removal of the Undaria pinnatifida canopy and the turf substratum (Corallina officinalis) in $25 \times 25 \mathrm{~cm}$ areas in the low shore at Rapaki Bay (treatments = -canopy+turf; -canopy-turf; +canopy+turf and +canopy-turf). Removals were done in autumn (March) and winter (July) and plots were monitored for $U$. pinnatifida recruits for 4 mo.

All analyses were carried out using multi-factorial ANOVA in Statistica v8. Homogeneity of variance was checked using Cochran's test and, where necessary, data were appropriately transformed to fulfill the assumptions of ANOVA. Post hoc analyses were carried out using Tukey's test.

\section{RESULTS}

\section{Natural recruitment patterns}

The natural recruitment of Undaria pinnatifida was negatively associated with the number of $U$. pinnatifida canopy-forming adult plants (Spearman's rank, $\mathrm{r}_{\mathrm{S}}=-0.13, \mathrm{p}=0.04, \mathrm{n}=240$; Fig. 1A), with most recruits occurring in areas that had a fewer than 8 adult plants per $0.25 \mathrm{~m}^{2}$. Maximum recruitment occurred where there was no adult canopy.

Natural recruitment was significantly greater in areas where the substratum was dominated by the coralline turf Corallina officinalis than in areas dominated by any other substratum type (one-way ANOVA, $F_{5,54}=43.57, \mathrm{p}<0.0001$; Fig. 1B). There appeared to be a high level of specificity in the relationship between recruitment success of Undaria pinnatifida and turfing coralline algae, with an order of magnitude more recruits in coralline turf than in
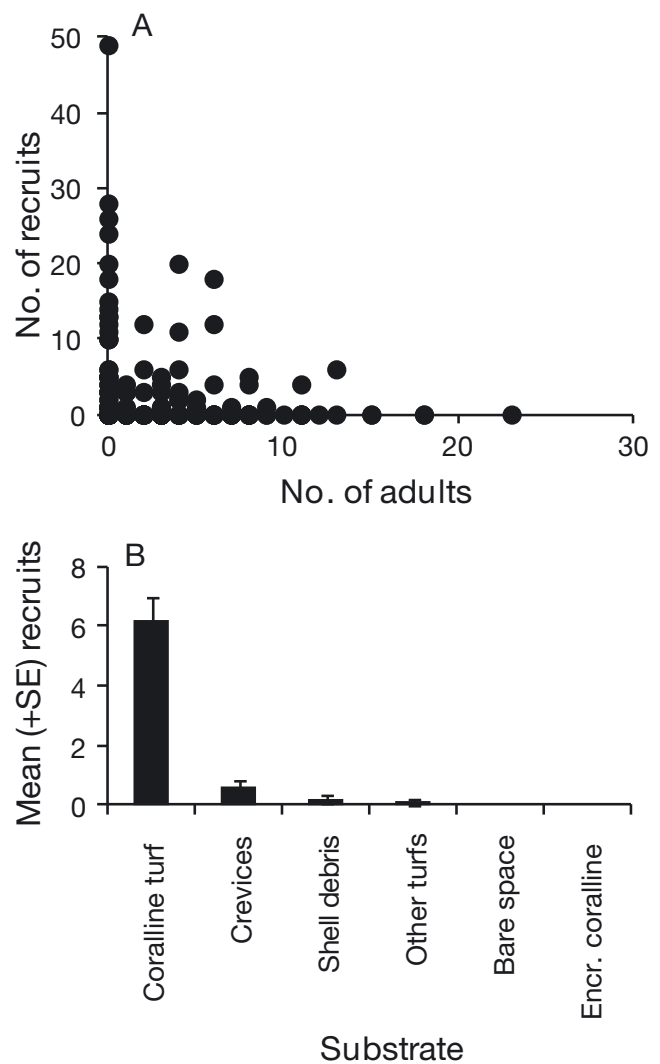

Fig. 1. (A) Number of Undaria pinnatifida recruits and adults per $0.25 \mathrm{~m}^{2}$ at Diamond Harbor over the period of monthly population sampling (June 2000-May 2002; Spearman rank correlation, $\mathrm{r}_{\mathrm{S}}=-0.13, \mathrm{p}=0.04, \mathrm{n}=240$ ), and $(\mathrm{B})$ the mean (+SE) number of recruits per $25 \times 25 \mathrm{~cm}$ area on each of 6 substratum types. Encr. coralline: encrusting coralline 
turf of a similar height of the brown alga Halopteris congesta ('other turfs' in Fig. 1B). Tukey's post hoc test also showed that recruitment into crevices and interstitial spaces in the substratum was significantly greater than recruitment into other turfing species, bare space and encrusting coralline algae. A few recruits appeared in shell debris. Of particular note was that there was no recruitment on the thin encrusting form of coralline algae.

\section{Native canopy and patch size effects on Undaria pinnatifida recruitment}

The absence of the native canopies significantly increased recruitment of both Carpophyllum maschalocarpum and Undaria pinnatifida (Fig. 2), with no recruits of either species occurring in the unmanipulated, canopy-dominated plots. The size of gaps within native C. maschalocarpum canopies significantly affected the recovery rate of $C$. maschalocarpum and the magnitude to which $U$. pinnatifida was able to invade. The smaller the disturbance area, the faster $C$. maschalocarpum recruitment and recovery occurred (Fig. 2A), with a peak in abundance during its summer recruitment period (December to February; size effect, $F_{2,273}=19.13, \mathrm{p}<0.001$ ). There was a gradient in recovery rate and size and, after 12 mo, approximately 100,75 and $30 \%$ of the areas were again covered by $C$. maschalocarpum in the $5 \times 5,25 \times 25$ and $50 \times 50 \mathrm{~cm}$ areas, respectively. In contrast, $U$. pinnatifida recruitment occurred mostly during spring (September to October 2001) and the following autumn (April 2002), reaching peak cover 2-3 mo later (Fig. 2B). Although U. pinnatifida recruited before C. maschalocarpum, it did not retain its cover because of the summer die-off of plants. The initial recruitment of $U$. pinnatifida in the smallest area $(5 \times 5 \mathrm{~cm})$ disappeared a month later and there was no subsequent invasion because C. maschalocarpum recaptured the space. The summer period of die-off of macroscopic $U$. pinnatifida allowed recruitment of C. maschalocarpum to occur without an overlying canopy. By the following autumn recruitment period of $U$. pinnatifida, C. maschalocarpum had begun to dominate space in the 2 larger clearances (size $\times$ time interaction, $F_{24,273}=1.71, \mathrm{p}=0.02$ ) Undaria pinnatifida reached $50 \%$ cover in these clearances in 2002 but again was declining later in the year as C. maschalocarpum cover increased. Control areas remained at $100 \%$ canopy cover of $C$. maschalocarpum throughout the 12 mo of this experiment, and there were no recruits of either species into any control plot.

\section{Conspecific canopy effects on Undaria pinnatifida recruitment}

Removal of the Undaria pinnatifida adult canopy resulted in a strong positive response of conspecific recruitment (Fig. 3). During winter and spring, there 


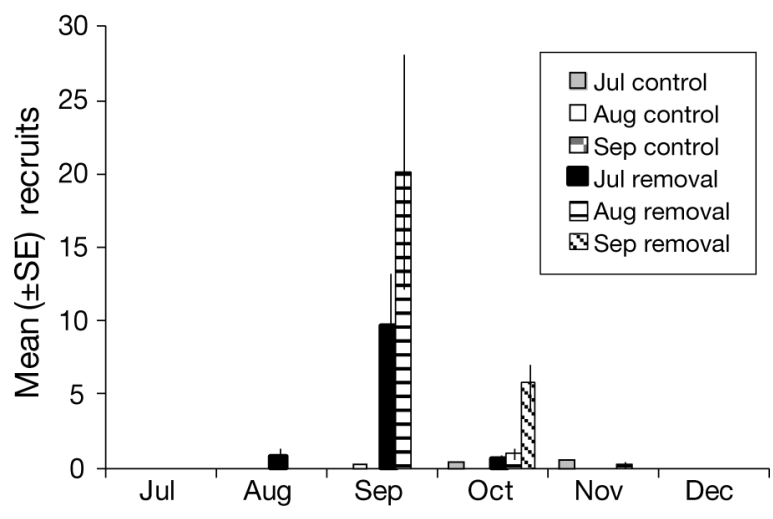

Fig. 3. Mean $( \pm \mathrm{SE})$ number of new recruits of Undaria pinnatifida per $0.25 \mathrm{~m}^{2}$ in control and $U$. pinnatifida canopy removal plots, initiated in July, August and September, between July and December 2001

was generally a 1 to 2 mo period between canopy removal and new recruits appearing, indicating the presence of at least an ephemeral propagule bank in the understory. Virtually no recruitment occurred within control areas (i.e. with canopies left intact). Following canopy removal in July and August there was a recruitment peak in September, and following removal of the canopy in September there was a peak, though slightly smaller, in October (these peaks generally correspond with the peaks in abundance in the late winter/spring cohort; see Fig. 2). All new recruits occurred either within the old holdfasts or within $\sim 50 \mathrm{~mm}$ of removed plants. There was no recruitment of any native fucoid into these clearances.

\section{Turfing algae, patch size and timing effects on Undaria pinnatifida recruitment}

There was no difference in the recruitment of Undaria pinnatifida in the substratum disturbance experiment between the 2000-2001 and 2001-2002 treatments $\left(F_{1,36}=0.06, \mathrm{p}=0.83\right)$ so data from the 2 years were combined. The great majority of recruits appeared in plots with coralline turf intact, compared to those where it had been removed $\left(F_{1,342}=60.2\right.$, $\mathrm{p}<$ 0.001; Fig. 4) but there was no difference in recruitment between the gap sizes (adjusted to numbers per $25 \times 25 \mathrm{~cm} ; F_{2,42}=2.7, \mathrm{p}=0.07$ ). Because there was no effect of disturbance size on recruitment of $U$. pinnatifida, subsequent experiments used a standard size of $25 \times 25 \mathrm{~cm}$.

When substratum clearances were carried out 8 times during the year, the timing of Undaria pinnati- fida recruitment was consistent across the periods (Fig. 5). There were 3 other notable features of this experiment. (1) Turf clearances carried out between November and April the following year all produced recruitment from March to May, and so a shift in the timing of disturbances had no effect on the period of recruitment (Fig. 5A-F). (2) The great preponderance of recruitment in the first year occurred in the areas where coralline turf remained intact. When these treatments were initiated, there was potential for artefacts because removal of turf may have also removed microscopic stages of $U$. pinnatifida, thereby biasing the experiment in finding recruitment mostly where turf was intact. However, many reproductively active $U$. pinnatifida adults remained around these clearances, so at least the November and December treatments would have had sporefalls and therefore would not be reliant on a propagule bank for recruitment. Nevertheless, recruitment occurred almost exclusively in the +turf treatments. (3) In the second season after each removal, U. pinnatifida had some recruitment into the -turf treatments. An examination of the substratum on which each recruit appeared showed that these were almost invariably onto places where the turf was recovering. Furthermore, a summer recruitment of the ephemeral algae Stictosiphonia spp. and Ectocarpus spp. occurred in the -turf plots, which may also have affected secondary recruitment of $U$. pinnatifida. These experimental effects were supported by a significant effect of substratum, month of disturbance

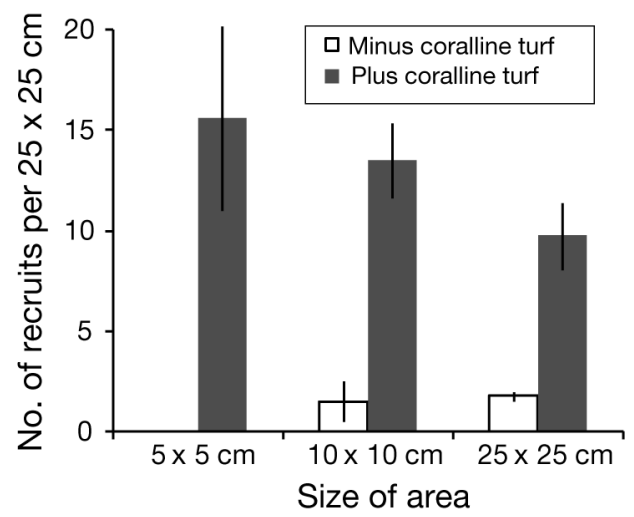

Fig. 4. Mean $( \pm \mathrm{SE})$ cumulative number of Undaria pinnatifida recruits per plot (numbers scaled up to per $25 \times 25 \mathrm{~cm}$ for standardization between treatments) in the 3 autumn months following disturbance initiation, with and without coralline turfing algae. Data here are combined for the November 2000 and October 2001 disturbances because there was no significant difference in recruitment across years 

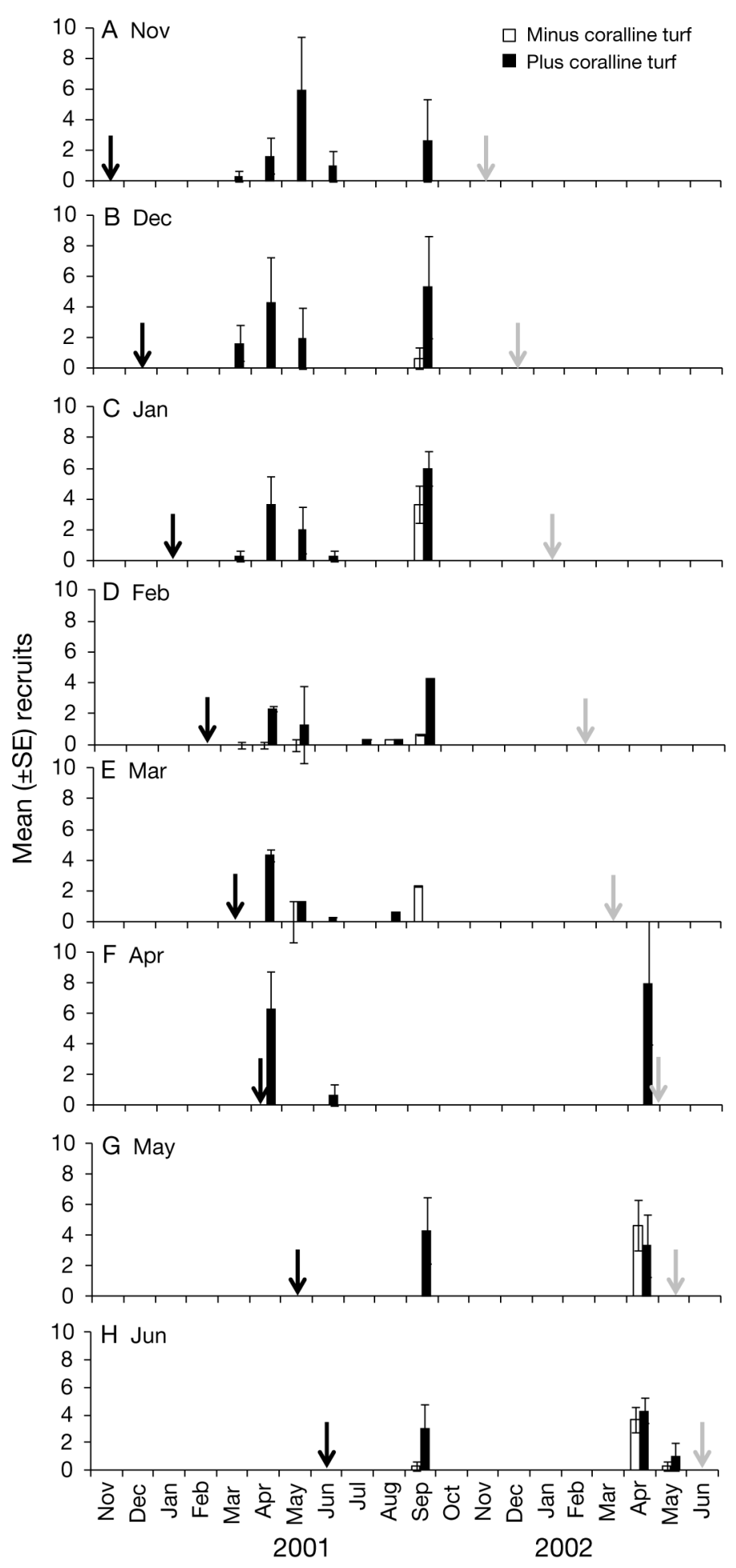

Fig. 5. Mean $( \pm \mathrm{SE})$ number of Undaria pinnatifida recruits per $25 \times 25 \mathrm{~cm}$ in plots with and without coralline turf. Each set of axes represents the month in which the coralline turf was removed (as indicated by the black arrow on the left). Plots were monitored monthly for 12 mo following each removal (i.e. final monitoring in each removal period is indicated by the grey arrow on the right) and time on $U$. pinnatifida recruitment $\left(F_{77,432}=1.59\right.$, $\mathrm{p}=0.02)$.

It should also be noted that grazers, especially the turbinid gastropod Turbo smaragdus, were present around the experiments. Turbo smaragdus occurred at densities of 1 to 2 individuals per $25 \times 25 \mathrm{~cm}$ area, but usually throughout the year there was no significant difference in its abundance between areas with and without turfing corallines (Thompson 2004).

In the experiment where recruitment of Undaria pinnatifida was tested across 2 turfing algal species, almost all recruits appeared in the coralline turf (no graphs shown). In the November 2000 plots, a total of 24 recruits appeared in the Corallina officinalis plots and none in the Halopteris congesta plots or in plots without turfing algae. In the October 2001 plots, a total of 14 recruits appeared in the C. officinalis plots, 1 in the $H$. congesta plots and none in the plots without turfing algae.

\section{Interactive effects of canopy and turfing algae on Undaria pinnatifida recruitment}

In the final experiment, there was a strong interactive effect between canopy and substratum. Over the course of a year and for all combinations of treatments initiated during March and July, Undaria pinnatifida recruitment occurred only in the -canopy+turf treatment (Fig. 6). In this treatment, there were up to $6.1 \pm 1.56$ and $2.8 \pm 1.37$ (mean \pm $\mathrm{SE}$ ) recruits per $25 \times 25 \mathrm{~cm}$ in peak months in the autumn (March) and winter (July) initiation periods, respectively.

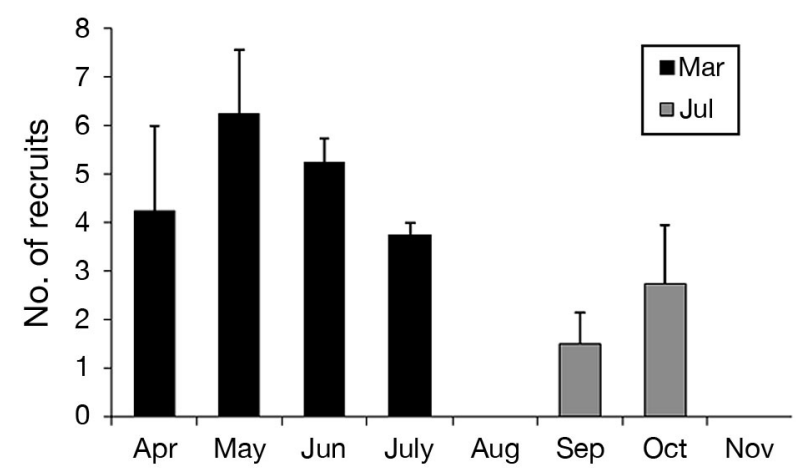

Fig. 6. Mean $(+\mathrm{SE})$ number of Undaria pinnatifida recruits per $25 \times 25 \mathrm{~cm}$ plot in experiment testing interactive effects of canopy and coralline turf. Treatments were initiated in autumn (March) and winter (July) and followed for 4 mo. Recruits occurred only in the +canopy-turf treatment, and so other treatments are not shown 


\section{DISCUSSION}

This study showed that both competition and facilitation are important processes in recruitment of the invasive kelp Undaria pinnatifida within native communities. Both intraspecific and interspecific competition by macroalgal canopies decreased or prevented recruitment, and it was unequivocal that a low-lying component of native communities, turfing coralline algae, substantially facilitated the establishment of the invasive kelp. These processes, acting in tandem with the prolific reproductive output of $U$. pinnatifida (Schiel \& Thompson 2012), give this species considerable traction into native communities.

Removal of the canopy of the locally dominant fucoid Carpophyllum maschalocarpum allowed recruitment of Undaria pinnatifida into gaps of all sizes. However, high, localized recruitment and expansion of C. maschalocarpum back into clearances diminished subsequent recruitment of $U$. pinnatifida. Partially, this was a matter of timing because $U$. pinnatifida sporophytes die off during the summer months of January to March (Schiel \& Thompson 2012), which is the period of peak recruitment of $C$. maschalocarpum (Schiel 1988). Once the native fucoid re-established, its growth and lateral spread of holdfasts affected subsequent recruitment of $U$. pinnatifida, particularly in the smallest patches. In these areas, therefore, C. maschalocarpum re-asserted dominance over the ensuing year.

The time lag in recruitment following removal of the dominant canopy-forming species was similar to that seen by Valentine \& Johnson (2003, 2004). This probably reflects light-related development from gametophytes to sporophytes, which generally takes 40 d (Stuart 1997). Valentine \& Johnson (2003, 2004) found that native canopy removal during the winter, just prior to the main sporophyll growing season of Undaria pinnatifida, produced peak recruitment. Unlike our populations, however, their subtidal Tasmanian populations had only one cohort annually, and so may not have had such a continuous propagule supply as those in our study, in which 2 cohorts appeared and for which propagules were present for most of the year (Schiel \& Thompson 2012). The most likely mechanism driving the canopy's suppressive effects on the growth of $U$. pinnatifida was competition for light. Valentine \& Johnson (2003) concluded that the canopy does not act as a physical barrier between spores and the substratum, and that it was competition for light rather than space that drove $U$. pinnatifida recruits to respond opportunistically in growth following removal of the canopy.
Both in Tasmania (Valentine \& Johnson 2003, 2004) and in our study in southern New Zealand, there seems to be no evidence that Undaria pinnatifida is capable of displacing large, habitat-forming native algal species through direct competition, because native assemblages generally recover to dominance following removal, despite seasonal blooms of $U$. pinnatifida in the winter and spring. However, the recruitment of $U$. pinnatifida in large abundances seems to be possible only following disturbances that remove canopies, particularly when underlying corallines are intact.

The exact mechanism of facilitation of coralline turf in the successful recruitment of Undaria pinnatifida requires testing, but most likely involves it being a 'safe site' (sensu Harper et al. 1961) for developing microscopic stages in the harsh conditions of the intertidal zone. These turfs retain moisture, largely preclude effective grazing by snails, have hard calcareous branches and thereby increase the habitat complexity on which kelp spores can settle and develop (Ceccherelli et al. 2002, Bulleri \& BenedettiCecchi 2008). These characteristics provide considerable advantages as micro-habitats compared with open reef areas, which can dry out over summer, and those covered by thin encrusting corallines, which slough off epithelial layers (Johnson \& Mann 1986). Ceccherelli et al. (2002) and Bulleri \& BenedettiCecchi (Bulleri \& Benedetti-Cecchi 2008) demonstrated that turfing algae in the Mediterranean facilitate the spread of Caulerpa species by providing increased habitat heterogeneity and physical complexity in the substratum, which entraps a greater number of spores. The facilitative relationship we found, however, appears to be species-specific, with non-coralline turfing algae of similar height to Corallina officinalis (e.g. Halopteris congesta) having little or no enhancing effect on recruitment of $U$. pinnatifida. Patches of other algal turfs are composed of soft fleshy algae, often with surface mucilage, that would not be conducive to spore settlement or development.

The positive relationship between invasive species and turfing algae, seen in ours and other studies, stands in contrast to the well-documented negative effects of turfing algae on recruitment of many native macroalgae (Dayton et al. 1984, Benedetti-Cecchi \& Cinelli 1992, Vadas et al. 1992, Cervin et al. 2004, Airoldi \& Beck 2007, Bellgrove et al. 2010, Schiel \& Lilley 2011). For example, Britton-Simmons (2006) showed that space pre-emption by low-lying algae inhibited recruitment of the invasive fucoid alga Sargassum muticum and that light reduction by 
canopies reduced its survival. Similarly, Sánchez \& Fernández (2006) found that bare space and increased nutrients facilitated establishment and spread of $S$. muticum. The suppressive role of lowlying algae found in these and other studies may well relate to the different attachment dynamics of fucoids, such as $S$. muticum, with quick attachment and direct development of $2 \mathrm{~N}$ propagules (e.g. Deysher \& Norton 1981), and laminarians such as Undaria pinnatifida, which must undergo weeks of development as gametophytes before fertilization and production of $2 \mathrm{~N}$ sporophytes (cf. Schiel \& Foster 2006). In the case of laminarians, therefore, some low-lying turfs may afford the necessary conditions for development in the intertidal zone, particularly relating to moisture retention. The facilitative relationship we found, however, between turfing corallines and $U$. pinnatifida recruitment occurred almost exclusively in the absence of macroalgal canopies, suggesting a suppressive role of light reduction in $U$. pinnatifida recruitment.

The role of grazers in this facilitative relationship between turfing corallines and Undaria pinnatifida recruitment is not entirely clear. There were occasional increases in the numbers of the dominant grazer, the turbinid gastropod Turbo smaragdus, in open areas of substrata (i.e. those with bare space and thin encrusting coralline algae), but other experiments (e.g. Thompson 2004) have found that grazers did not have significant effects on recruitment. Furthermore, this grazer affects mostly ephemeral algae and seems to have only slight effects on dominant species (Schiel 2006).

We were concerned about potential experimental artefacts in our disturbance experiments because of the possibility of removing propagule banks from disturbed areas. However, in all experiments and sampling of natural substrata, and across numerous controls, Undaria pinnatifida recruited almost exclusively into coralline turf, especially over the hot summer months, irrespective of removal time (e.g. before or after $U$. pinnatifida's reproductive period). Because of the absence of adults over summer, it is clear that micro-stages of $U$. pinnatifida survive over summer in these coralline turfs from which they form the following year's populations (Valentine \& Johnson 2003, Thompson 2004, Morelissen 2012, Schiel \& Thompson 2012). It is a matter of conjecture, however, whether it is slowly developing gametophytes or suppressed microscopic sporophytes that comprise this propagule cache. The development of both stages is affected by the light environment, which can add several months to development into visible sporophyte. Whatever the exact mechanism, however, it seems clear that facilitation by these turfs is fundamentally important to the success of $U$. pinnatifida at establishment and spread in these native communities.

The loss of habitat-forming, canopy macroalgal species and the corresponding increase in turfing algae are beginning to be seen as having a major role in the ecology of benthic communities and the spread of invasive species worldwide (Airoldi \& Beck 2007, Perkol-Finkel \& Airoldi 2010). Furthermore, as increasing stressors affect the coastal zone, turfing species are becoming increasingly dominant. It may well be the case, therefore, that the suppressive effects of larger species, such as the fucoids in our study, may diminish, and the facilitative effects of some turfing species may increase, as more species cross borders and establish in greater abundances within native communities (Ceccherelli et al. 2002, BrittonSimmons 2006, Airoldi \& Beck 2007, Valentine et al. 2007, Bulleri \& Benedetti-Cecchi 2008, Bellgrove et al. 2010, Perkol-Finkel \& Airoldi 2010, Schiel \& Lilley 2011). In southern New Zealand, these effects can be enhanced because, following disturbances to native fucoid canopies, turfing corallines not only expand but also cause a dramatic decrease in diversity that may last several years (Schiel \& Lilley 2007, 2011). If more stressors favour these turfs in future, their potential to enhance invasive species such as Undaria pinnatifida could lead to considerable shifts in community structure and function (cf. Tait \& Schiel 2011).

Acknowledgements. We thank Tuapapa Putuaio for a scholarship to G.A.T., and the New Zealand Foundation for Research, Science and Technology (now the Ministry of Science and Innovation) and the National Institute of Water and Atmospheric Research (particularly Simon Thrush) for continuing support of the research of D.R.S. We thank Jack van Berkel of the University of Canterbury Field Station for logistic support, Stacie Lilley and Paul South for their substantial contributions to this paper, and Mike Hickford, Dr Sharyn Goldstien and the members of the Marine Ecology Research Group for their help throughout.

\section{LITERATURE CITED}

Airoldi L (2000) Effects of disturbance, life histories, and overgrowth on coexistence of algal crusts and turfs. Ecology 81:798-814

Airoldi L, Beck MW (2007) Loss, status and trends for coastal marine habitats of Europe. Oceanogr Mar Biol Annu Rev 45:345-405

Airoldi L, Bulleri F (2011) Anthropogenic disturbance can determine the magnitude of opportunistic species repsosnes on marine urban infrastructures. PLOS ONE 6: e22985 
Baez JC, Olivero J, Peteiro C, Ferri-Yanez F, Garcia-Soto C Real R (2010) Macro-environmental modelling of the current distribution of Undaria pinnatifida (Laminariales, Ochrophyta) in northern Iberia. Biol Invasions 12: 2131-2139

> Bellgrove A, McKenzie PF, McKenzie JL, Sfiligoj BJ (2010) Restoration of the habitat-forming fucoid alga Hormosira banksii at effluent-affected sites: competitive exclusion by coralline turfs. Mar Ecol Prog Ser 419:47-56

> Benedetti-Cecchi L, Cinelli F (1992) Effects of canopy cover, herbivores and substratum type on patterns of Cystoseira spp. settlement and recruitment in littoral rockpools. Mar Ecol Prog Ser 90:183-191

Britton-Simmons KH (2006) Functional group diversity, resource preemption and the genesis of invasion resistance in a community of marine algae. Oikos 113:395-401

> Britton-Simmons KH, Abbott KC (2008) Short- and longterm effects of disturbance and propagule pressure on a biological invasion. J Ecol 96:68-77

Bulleri F, Benedetti-Cecchi L (2008) Facilitation of the introduced green alga Caulerpa racemosa by resident algal turfs: experimental evaluation of underlying mechanisms. Mar Ecol Prog Ser 364:77-86

$>$ Bulleri F, Bruno JF, Benedetti-Cecchi L (2008) Beyond competition: incorporating positive interactions between species to predict ecosystem invasibility. PLoS Biol 6: e162

Bulleri F, Tamburello L, Benedetti-Cecchi L (2009) Loss of consumers alters the effects of resident assemblages on the local spread of an introduced macroalga. Oikos 118: 269-279

> Bulleri F, Balata D, Bertocci I, Tamburello L, BenedettiCecchi L (2010) The seaweed Caulerpa racemosa on Mediterranean rocky reefs: from passenger to driver of ecological change. Ecology 91:2205-2212

Bulleri F, Alestra T, Ceccherelli G, Tamburello L, Pinna S, Sechi N, Benedetti-Cecchi L (2011) Determinants of Caulerpa racemosa distribution in the north-western Mediterranean. Mar Ecol Prog Ser 431:55-67

> Casas GN, Piriz ML, Parodi ER (2008) Population features of the invasive kelp Undaria pinnatifida (Phaeophyceae: Laminariales) in Nuevo Gulf (Patagonia, Argentina). J Mar Biol Assoc UK 88:21-28

> Ceccherelli G, Cinelli F (1999) The role of vegetative fragmentation in dispersal of the invasive alga Caulerpa taxifolia in the Mediterranean. Mar Ecol Prog Ser 182: 299-303

> Ceccherelli G, Piazzi L (2001) Dispersal of Caulerpa racemosa fragments in the Mediterranean: Lack of detachment time effect on establishment. Bot Mar 44:209-213

> Ceccherelli G, Piazzi L, Balata D (2002) Spread of introduced Caulerpa species in macroalgal habitats. J Exp Mar Biol Ecol 280:1-11

> Cervin G, Lindegarth M, Viejo RM, Aberg P (2004) Effects of small-scale disturbances of canopy and grazing on intertidal assemblages on the Swedish west coast. J Exp Mar Biol Ecol 302:35-49

> Dayton PK, Currie V, Gerrodette T, Keller BD, Rosenthal R, Ven Tresca D (1984) Patch dynamics and stability of some Californian kelp communities. Ecol Monogr 54: 253-289

> Dean PR, Hurd CL (2007) Seasonal growth, erosion rates, and nitrogen and photosynthetic ecophysiology of Undaria pinnatifida (Heterokontophyta) in southern New Zealand. J Phycol 43:1138-1148
Deysher L, Norton TA (1981) Dispersal and colonization in Sargassum muticum (Yendo) Fensholt. J Exp Mar Biol Ecol 56:179-195

Dunstan PK, Johnson CR (2007) Mechanisms of invasions: can the recipient community influence invasion rates? Bot Mar 50:361-372

Edgar GJ, Barrett NS, Morton AJ, Samson CR (2004) Effects of algal canopy clearance on plant, fish and macroinvertebrate communities on eastern Tasmanian reefs. J Exp Mar Biol Ecol 312:67-87

Engelen A, Santos R (2009) Which demographic traits determine population growth in the invasive brown seaweed Sargassum muticum? J Ecol 97:675-684

Farrell P, Fletcher RL (2006) An investigation of dispersal of the introduced brown alga Undaria pinnatifida (Harvey) Suringar and its competition with some species on the man-made structures of Torquay Marina (Devon, UK). J Exp Mar Biol Ecol 334:236-243

> Forrest BM, Blakemore KA (2006) Evaluation of treatments to reduce the spread of a marine plant pest with aquaculture transfers. Aquaculture 257:333-345

Forrest BM, Taylor MD (2002) Assessing invasion imapct: survey design considerations and implications for management of an invasive marine plant. Biol Invasions 4: 375-386

> Harper JL, McNaughton IH, Sagar GR, Clatworthy JN (1961) Evolution and ecology of closely related species living in same area. Evolution 15:209-227

Hay CH, Villouta E (1993) Seasonality of the adventive Asian kelp Undaria pinnatifida in New Zealand. Bot Mar 36:461-476

Hewitt CL, Campbell ML, McEnnulty F, Moore KM, Murfet NB, Robertson B, Schaffelke B (2005) Efficacy of physical removal of a marine pest: the introduced kelp Undaria pinnatifida in a Tasmanian marine reserve. Biol Invasions 7:251-263

Incera M, Bertocci I, Benedetti-Cecchi L (2010) Effects of mean intensity and temporal variability of disturbance on the invasion of Caulerpa racemosa var. cylindracea (Caulerpales) in rock pools. Biol Invasions 12:501-514

Irigoyen AJ, Trobbiani G, Sgarlatta MP, Raffo MP (2011) Effects of the alien algae Undaria pinnatifida (Phaeophyceae, Laminariales) on the diversity and abundance of benthic macrofauna in Golfo Nuevo (Patagonia, Argentina): potential implications for local food webs. Biol Invasions 13:1521-1532

> Johnson CR, Mann KH (1986) The crustose coralline alga Phymatolithon inhibits the overgrowth of seaweeds without relying on herbivores. J Exp Mar Biol Ecol 96: 127-146

Lilley SA, Schiel DR (2006) Community effects following the deletion of a habitat-forming alga from rocky marine shores. Oecologia 148:672-681

Martin JP, Cuevas JM (2006) First record of Undaria pinnatifida (Laminariales, Phaeophyta) in Southern Patagonia, Argentina. Biol Invasions 8:1399-1402

Mineur F, Johnson MP, Maggs CA (2008) Non-indigenous marine macroalgae in native communities: a case study in the British Isles. J Mar Biol Assoc UK 88:693-698

Morelissen B (2012) Ecological effects of Undaria pinnatifida (Harvey) Suringar and nutrient-enrichment on intertidal assemblages in the Wellington region of New Zealand. PhD thesis, Victoria University of Wellington, Wellington

Parsons MJ (1995) Status of the introduced brown seaweed Undaria in New Zealand. Conservation Advisory Sci- 
ence Notes No. 112, New Zealand Department of Conservation, Wellington

Pedersen MF, Staehr PA, Wernberg T, Thomsen MS (2005) Biomass dynamics of exotic Sargassum muticum and native Halidrys siliquosa in Limfjorden, Denmark: implications of species replacements on turnover rates. Aquat Bot 83:31-47

Perkol-Finkel S, Airoldi L (2010) Loss and recovery potential of marine habitats: an experimental study of factors maintaining resilience in subtidal algal forests at the Adriatic Sea. PLoS ONE 5:e10791

> Primo C, Hewitt CL, Campbell ML (2010) Reproductive phenology of the introduced kelp Undaria pinnatifida (Phaeophyceae, Laminariales) in Port Phillip Bay (Victoria, Australia). Biol Invasions 12:3081-3092

Raffo MP, Eyras MC, Iribarne OO (2009) The invasion of Undaria pinnatifida to a Macrocystis pyrifera kelp in Patagonia (Argentina, south-west Atlantic). J Mar Biol Assoc UK 89:1571-1580

Russell LK, Hepburn CD, Hurd CL, Stuart MD (2008) The expanding range of Undaria pinnatifida in southern New Zealand: distribution, dispersal mechanisms and the invasion of wave-exposed environments. Biol Invasions 10:103-115

> Sánchez I, Fernández C (2006) Resource availability and invasability of an intertidal macroalgal assemblage. Mar Ecol Prog Ser 313:85-94

Scheibling RE, Gagnon P (2006) Competitive interactions between the invasive green alga Codium fragile ssp. tomentosoides and native canopy-forming seaweeds in Nova Scotia (Canada). Mar Ecol Prog Ser 325:1-14

$>$ Schiel DR (1985) Growth, survival and reproduction of two species of marine algae at different densities in natura stands. J Ecol 73:199-217

Schiel DR (1988) Algal interactions on shallow subtidal reefs in northern New Zealand: a review. NZ J Mar Freshw Res 22:481-489

Schiel DR (2006) Rivets or bolts? When single species count in the function of temperate rocky reef communities. J Exp Mar Biol Ecol 338:233-252

Schiel DR (2011) Biogeographic patterns and long-term changes on New Zealand coastal reefs: non-trophic cascades from diffuse and local impacts. J Exp Mar Biol Ecol 400:33-51

Schiel DR, Foster MS (2006) The population biology of large brown seaweeds: ecological consequences of multiphase life histories in dynamic coastal environments. Annu Rev Ecol Evol Syst 37:343-372

Schiel DR, Lilley SA (2007) Gradients of disturbance to an algal canopy and the modification of an intertidal community. Mar Ecol Prog Ser 339:1-11

Schiel DR, Lilley SA (2011) Impacts and negative feedbacks in community recovery over eight years following removal of habitat-forming macroalgae. J Exp Mar Biol Ecol 407:108-115

Editorial responsibility: Laura Airoldi, Ravenna, Italy
Schiel DR, Thompson GA (2012) Demography and population biology of the invasive kelp Undaria pinnatifida on shallow reefs in southern New Zealand. J Exp Mar Biol Ecol 434-435:25-33

Silva PC, Woodfield RA, Cohen AN, Harris LH, Goddard JHR (2002) First report of the Asian kelp Undaria pinnatifida in the northeastern Pacific Ocean. Biol Invasions 4: 333-338

Stuart MD (1997) The seasonal ecophysiology of Undaria pinnatifida (Harvey) Suringar in Otago Harbour, New Zealand. PhD thesis, Otago University

Stuart M (2004) Review of research on Undaria pinnatifida in New Zealand and its potential impacts on the eastern coast of the South Island. Department of Conservation Internal Series 166, New Zealand Department of Conservation, Wellington

Tait LW, Schiel DR (2011) Legacy effects of canopy disturbance on ecosystem functioning in macroalgal assemblages. PLoS ONE 6:e26986

Thompson GA (2004) Mechanisms of invasion and persistence of the invasive kelp Undaria pinnatifida (Harvey) Suringar within intertidal areas of southern New Zealand. PhD thesis, University of Canterbury, Christchurch

Thomsen MS, Wernberg T, Tuya F, Silliman BR (2009) Evidence for impacts of nonindigenous macroalgae: a meta-analysis of experimental field studies. J Phycol 45: 812-819

Thomsen MS, Wernberg T, Olden JD, Griffin JN, Silliman BR (2011) A framework to study the context-dependent impacts of marine invasions. J Exp Mar Biol Ecol 400: 322-327

Uwai SY, Nelson W, Neill K, Wang WD and others (2006) Genetic diversity in Undaria pinnatifida (Laminariales, Phaeophyceae) deduced from mitochondria genes origins and succession of introduced populations. Phycologia 45:687-695

$>$ Vadas SRL, Johnson S, Norton TA (1992) Recruitment and mortality of early post-settlement stages of benthic algae. Br Phycol J 27:331-351

Valentine JP, Johnson CR (2003) Establishment of the introduced kelp Undaria pinnatifida in Tasmania depends on disturbance to native algal assemblages. J Exp Mar Biol Ecol 295:63-90

> Valentine JP, Johnson CR (2004) Establishment of the introduced kelp Undaria pinnatifida following dieback of the native macroalga Phyllospora comosa in Tasmania, Australia. Mar Freshw Res 55:223-230

> Valentine JP, Magierowski RH, Johnson CR (2007) Mechanisms of invasion: establishment, spread and persistence of introduced seaweed populations. Bot Mar 50: 351-360

Wotton DM, O'Brien C, Stuart MD, Fergus DJ (2004) Eradication success down under: heat treatment of a sunken trawler to kill the invasive seaweed Undaria pinnatifida. Mar Pollut Bull 49:844-849

Submitted: May 7, 2012; Accepted: August 13, 2012

Proofs received from author(s): October 30, 2012 